\title{
The perspective of Gestalt therapy in social work practice
}

\author{
Alina Petrauskiene*, Irena Zemaitaityte, and Vida Grigaliene \\ Mykolas Romeris University, Lithuania
}

\begin{abstract}
The paper analyzes social work integrating the principles of Gestalt therapy, such as dialogue and phenomenological approach, internalization, responsibility and creative adaptation. The main perspectives of Gestalt therapy, which are related to the cases of social work, contexts and possibilities of therapeutic work, are highlighted. The article also reveals obstacles (e.g. dominant, patronizing, controlling and expert model of client assistance, isolated and restricted by directives the reality of social work, institutionalized social work practices and bureaucratic dependence of social security) that impede the development of therapeutic social work in Lithuania. It can be argued that the perspective for Gestalt therapies is available to social workers who seek therapeutic social work practice methodologies, help relationships, and empower clients for change.
\end{abstract}

Key words: therapeutic social work, Gestalt therapy principles, institutionalized social work practice.

\section{Introduction}

Scientific literature provides arguments and perspectives that show that social workers can approach their work creatively and satisfy the needs of their clients using various methods in different theoretical directions: existentialism, behaviourism, sociological system theory, ecological theory, critical theory, etc. It means that in the theoretical sense, that social workers stand in front of a wide open horizons for the search for methodological practices [1]. Scientists [1] analyzed the existentialist paradigm in social work and grounded the needs, possibilities and constraints of individual therapeutic work with clients. The authors paid attention to the existentialist attitude of the social worker as a therapist and her personality's ability to establish a strong interpersonal relationship with the client and in this way influence the client. It is based on the understanding that social work clients are people who experience life-threatening crises related to suicide, aggressive behaviour, violence manifestations, tragedies of family relationships, have the history of unloved and abandoned children, various addictions, mental illnesses, and live through other situations. Critical situations of social work clients, such as the separation of children from parents, loss of life, painful experiences of clients, highlight not only the needs of professional social, but also, especially, timely therapeutic assistance. The relationship between the social worker and the client is recognized as one of the key factors in such assistance [2].

\footnotetext{
* Corresponding author: alina@mruni.eu
} 
Researchers [3-7] explored the dialogue-based social worker-client relationship in order to establish a contact and enable the client to change. Researchers $[8,9]$ point out that the principles of Gestalt therapy and social work are coherent, such as: interaction between the client and the environment, understanding of the individual / client situation, empathybased aid relationships, identification of the client's strengths (ecological approach) and selfrealization recognition. Senreich [8] examined the application of theoretical ideas of Gestalt therapy - the "I-You" relationship, field theory, creative adaptation and phenomenology, based on cases from social work practice. Bourque and Sherlock [10] analyzed the application of Gestalt therapies to the treatment by social workers to oncologic patients. Muth [11] revealed the importance of dialogue (according to Buber, 1998 [19]) in developing a social work process with clients from different cultures and social strata. Melnick and Nevis [12] described in detail in the book "Mending the World: Social Healing Interventions by Gestalt Practitioners Worldwide" 13 examples of community-based social work from different parts of the world, dealing with such issues as natural disasters, the fight against AIDS, and political conflicts. Marais and Van der Merwe [13] explored the development of relationships of social workers while working with children in rural areas. Pavlovsky [14] believes that Gestalt therapy is ideal for establishing and maintaining relationships with homeless children and adolescents in social work when outreaching the clients in their whereabouts.

The aim of this article is to examine the perspective of Gestalt therapy in the practice of social workers and limitations of the implementation of therapeutic social work.

The article is based on the analysis of scientific literature. Selected publications of foreign and Lithuanian scientists are highlighting the ideas of humanistic and existential trends in social work, Gestalt therapy and social work principles compatibility, creating a relationship between a social worker and a client in the process of assistance.

\section{Application of Gestalt therapy principles in social work practice}

\subsection{Dialogue and phenomenological approach are key components of the aid relationship}

The Gestalt therapy theory emphasizes authentic dialogue, since its premise is emphasizing that people are naturally inclined to interact and instinctively develop relationships with others in order to develop themselves as personalities [7, 8]. According to Melnick and Nevis [12], the essential ingredient in Gestalt therapy is the use of methods that support authentic and self-disclosing dialogue. Gestalt's practice places a great emphasis on such dialogue and contact. In a dialogue everyone can express themselves and hear other feelings, values, aspirations. A dialogue is much more than words, it is also an expression of how a person speaks, what his posture, body language. This is a natural way people can "reach" or "touch" each other.

Dialogue is essential in building trust. In a social work process between a worker and a client, there should be developed sincere, non-valuing and non-intrusive, dialogue-based relationships in which the assisting professional is involved as an equivalent partner of an encounter. The therapeutic relationship, which is the process of contact creation in time, is the soul of a Gestalt therapy, and something that the provider of aid and the client can intuitively feel. It is a powerful tool for dealing with client problems and a medium for growth and change. Only when the relationship is created will the clients be prepared to explore the most sensitive areas of their lives [15]. It is precisely the dialogue aspect that determines that the helping relationship between the social worker and the client is the main component of the aid [16]. 
According to Congress [9] the key in professional help is authenticity - being present, open, and sincere with the client. Yontef [16] also emphasizes the need to be as authentic as possible "here and now" so that the "I-You" contact become possible. Often, such a relationship is sufficient to become healing, allowing for a change to happen. The "I-You" contact in Gestalt therapy theory is emphasized as essential in the relationship between a helping professional and a client. Using the Gestalt The "I-You" dialogue can substantially improve the quality and efficiency of social worker's work. When working with different client groups (e.g. risk families, addicts, homosexual clients, etc.), the "I-You" dialogue encourages social workers not to be based, do not take prior assumptions in dealing with clients. Authenticity, sincerity, respect and humanity - are listed by the theory of social work as indispensable features of aid relationships.

Marais and Van der Merwe [13], who have explored the factors that influence the development of relationships in social work with children in rural areas, also hold a dialogue an important factor in involving children in the aid process. According to the authors, the client's experience is transmitted through a dialogue that is more than words and includes what is "between" the client and the social worker. The "dialogue" aspect of the aid relationship makes it the most important aid component.

Bourque and Sherlock [10], who have explored the use of Gestalt therapy in social work with patients with oncologic diseases, argue that authentic contact between a social worker and a client provides a sense of clarity and comfort to the client and satisfies the social worker. And a creative, non-authoritative Gestalt approach creates opportunities for helping clients more easily accept their changed situation just after hearing a diagnosis, and later experiencing anxiety, confusion, grief and despair.

The dialogue between the social worker and the client is based on reciprocal revelation. It is a ratio in which both parties grow as personalities, albeit not necessarily equal parts. However, Senreich [8] points out that the "I-You" relationship between a client and a helping professional does not mean that a social worker can freely disclose personal information and open up her feelings, regardless of whether they relate to the client's situation. Opening up from a social worker is acceptable only to the extent that it serves the client's benefit. The "I-You" ratio means that the social worker takes an unauthorized approach, where the relationship between the social worker and the client is not only hierarchical - vertical, but equally horizontal - [16]. A social worker and a client perform different roles in aid relationships, but the social worker is not the one who knows more than a client, as the latter should deal with difficulties in his life or existential talents. In other words, the social worker can have a lot of professional knowledge about the methods and resources of help that can help the client in his situation and promote his self-realization, but he should not be an "expert" who can tell how others should live their lives. In turn, the client clearly understands what is going on with him and how he contributes to this relationship. From the point of view of Gestalt, the "I-You" relationship fosters respect for the client's choice, his attitude, respect for his dignity and self-determination [8].

Senreich [8] points out that the "I-You" ratio in social work practice is also needed. In the "I-It" relationship we aim for a goal, we "do" more than we "are", but the pursuit of goals is an important part of the relationship between the social worker and the client. Moreover, making assumptions about a person's life situation, health status, diagnosis, gender, race, age or sexual orientation is also a part of the "I-It" attribute. Of course, social workers often rely on such an approach by providing help or service plans for working with specific problem groups or categories of social service users.

Pavlovsky [14] also emphasizes the controlled involvement of the social worker and the authenticity of the aid relations. A social worker can rarely be benignly neutral or always be positively empathetic. He often gets involved, he has to express his opinion, even if he 
is careful not to hit her client. Controlled engagement used in Gestalt therapy can be useful here, which can be applied in helping the client formulate their own attitude.

\subsection{Phenomenological approach}

Phenomenological approach helps the provider of aid to maintain non-judgmental and nonvaluing attitude towards the client, to understand the subjective experience of the client, expressed in words or non-verbal form. Phenomenological approach can help a social worker to accept individual and cultural differences. Phenomenological approach gives people a much more flexible and less critical look than many other principles of psychotherapy on which social work practice is based. A social worker can in phenomenological way monitor the subjective attitude of the client towards what was happening in his or her past, or, for example, what is happening between him and the client's work in the office, in view of their two interactions, the client's body language, intonation, etc. Based on the phenomenological viewpoint, the social worker tries to "bracket" his earlier assumptions and beliefs about the client as much as possible. It means abandoning its usual attitude and focusing on "here and now" experience, thus potentially expanding and complementing the perception of the client and his situation [8].

As a social worker often has to interact with other cultures, the ability to "bracket" can help him stay alert and not reflect his cultural preferences for the client. The advantage of a gestalt approach is that differences are not only tolerated but also valued. Being different is normal and even necessary for growth. In addition, by acting forces, which promote a change, opposite forces are also emerging to stabilize and maintain the current situation. A social worker must respect this resistance, remain open, curious, and do not become condemned or despised [12].

\section{Awareness, responsibility and creative adaptation - empowering the client in relational relationships}

Gestalt therapy pays special attention to the client experience "here and now", using it as a way to expand the client's awareness, how one lives, and how one works [8]. The more an individual or group becomes aware of the situation, the more likely it is that they will have several choices, and the more likely they will be able to find energy to act. Awareness involves a range of inner senses, feelings, thoughts, insights, fantasies, aspirations and a spectrum of dreams. It covers external aspects and behaviors in social interaction, as well as environmental conditions and context that determine what can be achieved at a particular time [12].

Creative adaptation, i.e. human effort to meet one's needs in one's best interest in a particular situation at that time depends on personal abilities, skills, previous experience, family, community, culture, social traditions and customs, social exclusion, resource availability, and other factors. Creative adaptation is a very broad concept that includes survival skills, defense mechanisms, and psychiatric symptoms. Although literally this concept is usually associated with an individual, it can also be applied to families, communities, in terms of meeting their social needs [8]. It is perfectly suited to the approach in social work that rest son strengths because creative adaptation means that every moment a person does the best he can. Adapting the individual's behaviour in society can be treated as a creative adaptation. From the point of view of Gestalt theory, symptoms or behavioral difficulties are viewed not as problems but as an individual's creative adaptation. For example, a teenager who does not receive proper attention at home and who is not successful at school may have a creative adaptation with a gang that accepts and understands the teenager. Or, if 
a depressed young man "discovers" that heroin relieves emotional pain, addiction to drugs will be his creative adaptation. So, based on the Gestalt's point of view, a social worker does not consider the client's problems as a pathology. Instead, they are treated as an attempt by the client to meet one's needs based on one's experience and the environmental resources available to the client. It helps to form non-valuing and non-judgmental approach to aid relationships. Additionally, creative adaptation also means that people can adapt creatively not only by doing the best they can in a particular situation, but also by learning new ways that can give them greater satisfaction for themselves and for other people they interact with. Thus, an important aspect of the aid relationship between the social worker and the client is to help a person to adapt creatively, find new ways of self-realization, thus enabling the client to act more effectively and better adapt to one's situation. Creative adaptation involves the concept of self-regulation of the body used by Gestalt therapies, whereby all living organisms in an environment seek balance in an optimal way, using available resources [17]. So, based on this concept, the quality of creative adaptation solutions depends on maintaining the environment that helps people meet their needs. In other words, people can better realize themselves in an environment where growth-enhancing resources are sufficient. Therefore, based on this point of view, social workers seek to provide customers with the necessary information, services and resources and enable a person, family or community to search for new ways to meet their needs.

Melnick and Nevis [12] also emphasize an approach based on strengths: in Gestalt view, it is attempted to find what people do good and seek change through developing their competence and positive values. Both individuals and social systems have strong and weak sides. In the opinion of the authors, if the social worker concentrates on what is wrong and will try to eliminate these shortcomings, hoping that this will solve the problem. This can only further aggravate the situation, especially at the beginning of the aid process when the client's trust in the social worker is poor. The emphasis on negative things usually reduces and often stops people's energy. Undoubtedly, dysfunctional behavior should not be tolerated, but starting from what works well on the system, make sure that people see and recognize it and then use it as a supportive way to tackle those things that are bad.

Bourque and Sherlock [10] note that Gestalt therapy emphasizes personal responsibility. This is in line with the client's empowerment concept in social work, because when it comes to understanding the situation and assuming responsibility for the decisions made, the client acquires the power to manage his or her own life. The better the client understands his situation and the ways in which he acts, assumes responsibility for the decisions made and helps the social worker to seek new ways of creative adaptation, the more he is empowered to "take his life into his own hands", to concentrate efforts to change it, to take an active position, discover new, previously unknown internal resources, take on emerging challenges and see them as opportunities.

According to Senreich [8], the Gestalt approach to social work practice canbe described as follows: Individuals try to get out of the environment what they need, doing the best they can at the time. The ways in which they do this depend on the resources available to them at that time and on their previous experiences of life. In this respect, each person is unique. The role of a social worker is to help clients meet their needs in the most favorable ways for them, helping them to access resources that allow them not only to survive, but also grow up as personalities. The direct application of gestalt principles is possible in the context of genuine communication between a social worker and a client, where social workers, by doing the best they can, try to explore and understand their customer experience without appreciating or disregarding it. This applies not only to individual clients, but also to families and communities. 


\section{Obstacles to the development of therapeutic social work in Lithuania}

\subsection{A dominant, patronizing, controlling and expert customer support model}

The patronizing model of relationships used in social work practice ignores customer autonomy and empowerment $[6,18]$. The tendency of social workers to dominate, ignore the client's position and balance at the intersection of professional and familiar relationships creates preconditions for inequalities between the social worker and the client, when a social worker becomes an expert in a client's situation, seeking to dominate the aspects of time and decisions. A more significant area of ignoring the client's opinion is observed in public sector social workers' function, as well as in non-governmental social service organizations. The tendency of social workers to make decisions about the client and to ignore the client's opinion is more pronounced in the residential closed social care and nursing institutions (Lithuanian context).

The coordination of control and assistance functions in social work practice, the ability to solve the ethical dilemmas arising from the aid process requires a certain strategy of the social worker's attitude and customer relationship. When a social worker sees herself not only as an "expert" but also as a "controller", supervising and guarding a client, there can be no language about the equivalent relationship between a social worker and a client. "An example could be when social workers do not see professional dilemmas when they have to report illegal employment or intimate relationships so that the clients were cut off received social benefits. These specialists are considered as social work control of their clients and documentation of their cases. For justice's sake, it should be noted that social work inevitably has to combine the functions of control and aid ... but when the aim of the work is solely control, it no longer makes sense to involve professionals of social work, such functions of citizens' "checking" may be carried out by other municipal public order support staff" [6].

\subsection{Isolated and limited by directives the reality of social work}

The researchers [5] note that the situations of social work practice, where employees, in spite of good intentions, can inhibit their clients by suppressing their initiative. Another obstacle arises, when social workers do not feel empowered, they will not take the initiative to help the client "here and now" and are afraid to be accused by their managers or administration. According to the authors, social workers, unable to act themselves cannot enable others / clients to change: "If a social worker is a person who feels powerless or isolated from participating in decision-making in an organization, proposing alternatives and converting their work only to the execution of directives, "trouble shooters" or "lone warriors in the battlefield", etc., the social worker will not enable the other. Enforcement involves accepting a certain risk, so if the organization is dominated by the culture of "witch hunting", one way to stay a social workers is to accept a "no involvement" stand, unless one is involved directly, try to "deal with problems" on one's own and not to question the management. What's more, it is likely to happen that the issues raised by a social worker label this person as "problem brewing" and unable to cope with one's work? [5]. The bureaucratic provision of social services implemented by social workers is characterized by the low involvement of service users / clients as equivalent partners in solving their own social problems and having little effect on what services they would need. Bureaucratic social work focuses on material and instrumental assistance, while the relationship with the client and his understanding of emotional needs play a secondary role. 


\subsection{Institutionalized social work practice and bureaucratic social security dependence}

Until now (in Lithuania) the discussion is held whether the social work profession is autonomous or it is based on expert judgment in solving certain social problems of social groups, or is social work, after all, a kind of tool for state bureaucracy and control? If a professional social work practice is seen as an institutionalized practice in which the nature of the social work institutions explicitly and in a structured manner refers to the functions and roles of social workers, then the structure of the social work process is characterized by the setting of goals and objectives and by setting the time limits within which these tasks must be performed. This functional, regulated by rules activity creates a productoriented result-oriented model of social work. In the practice of social work, it is possible to notice a lot of urgency, fast-paced results, rational and technical work process focused on instrumental, material customer support, less attention is given to listening to the client, emotionally supporting, and promoting one's autonomy. The urgent, technical and routine work of social workers, lack of time and high workload pose a risk to the client, as the client can become a passive recipient, or even psychologically dependent on social support [3].

\section{Main findings}

Gestalt therapy can be substantiated as the original theoretical and practical perspective of social work, used to create aid relationships, enabling clients to change and accompanying them along. The article highlights a number of obstacles that hinder the dissemination and development of therapeutic social work in practice. Nevertheless, the prospects for Gestalt therapy are recognized by social work theorists and justified in cases of social work. This is opportunity for social workers to consider new topical methods of therapeutic social work practice, adequate preparation of social workers, responding to the up-rising daily needs of the clients and the necessity of the development of the profession, linked to existential, humanistic social work.

\section{References}

[1] N. Bogdanova, B. Švedaitè-Sakalauskè, Acta Paedagogica Vilnensia 24, 9-19 (2010)

[2] M. Smith, M. Doel, A. Cooper, J. Simmonds, R. Solomon, R. Kohli, Relationshipbased social work: Getting to the heart of practice (Jessica Kingsley Publishers, 2010)

[3] A. Kiaunytè, D. Puidokienè, Acta Paedagogica Vilnensia 27, 124-138 (2011)

[4] L. Gvaldaitè, STEPP: Socialinè teorija, empirija, politika ir praktika 5, 42-53 (2009)

[5] J. Ruškus, N. Mažeikienè, R. Naujanienè, R. Motiečienè, Socialinis darbas, Patirtis ir metodai 12(2), 9-43 (2013)

[6] B. Švedaitè-Sakalauskè, L. Gvaldaitè, J. Buzaitytė-Kašalynienè, Socialinè teorija, empirija, politika ir praktika 9, 21-36 (2014)

[7] S. Natland, Dialogical Communication and Empowering Social Work Practice (2017), https://doi.org/10.1080/15433714.2014.954945

[8] E. Senreich Smith, College Studies in Social Work 84(1), 55-75 (2014), https://doi.org/10.1080/00377317.2014.860796

[9] E.P. Congress, Gestalt Theory and Social Work Treatment (Oxford University Press, 2011)

[10] N. Bourque, E. Sherlock, Social Work in Mental Health 15, 143-158 (2017), https://doi.org/10.1080/15332985.2016.1191583 
[11] C. Muth, J. Soc. Work Pract. 23(2), 201-213 (2009)

[12] J. Melnick, E.C. Nevis, Mending the world: Social healing interventions by Gestalt practitioners worldwide (Taylor \& Francis, 2016)

[13] C. Marais, M. Van der Merwe, Social Work/Maatskaplike Werk 52(2), 145-166 (2016)

[14] А.И. Павловский, Консультативная Психология и Психотерапия 4, 188-213 (2009)

[15] W.P. Panning, Gestalt Therapy (Oxford University Press, 2009)

[16] G.M. Yontef, Awareness, dialogue \& process: essays on Gestalt therapy (The Gestalt Journal Press, 1993)

[17] Ф. Перлз. Эго, голод и агресия (Москва: “Смысл”, 2000)

[18] R. Makštutytė, L. Vaškevičiūtè, Socialinis darbas, Patirtis ir metodai 8(2), 23-37 (2011)

[19] M. Buber, Dialogo principas I: Aš ir tu (Vilnius: Katalikụ pasaulis, 1998) 